\title{
NEW COLUMN CONFIGURATIONS FOR PRESSURE SWING BATCH DISTILLATION I. FEASIBILITY STUDIES
}

\author{
Modla G. and P. Lang \\ Budapest University of Technology and Economics, \\ Department of Process Engineering, H-1521 Budapest, Muegyetem rkp. 3-5 \\ www.vegyelgep.bme.hu,lang@mail.bme.hu
}

\begin{abstract}
The feasibility of the pressure swing distillation in different batch column configurations is investigated. The method is based on the assumption of maximal separation. Besides studying the well known batch configurations (rectifier, stripper, middle vessel column) we also suggest two novel configurations such as double column batch rectifier and double column batch stripper. We also study the alternate application of a rectifier and a stripper. $\quad$ Copyright C 2007 IFAC
\end{abstract}

Keywords: Pressure Swing Distillation, Batch Column Configurations, Feasibility Study

\section{INTRODUCTION}

Distillation is the separation method most frequently applied in the chemical industry, which is based on the difference of volatility of the components of a liquid mixture. For the separation of the two components $(\boldsymbol{A}$ and $\boldsymbol{B})$ forming an azeotrope a special distillation method must be applied such as the pressure swing distillation (PSD), extractive or heteroazeotropic distillation.

Batch distillation (BD) has always been an important part of seasonal, uncertain or low capacity and highpurity chemicals' production. It is a process of key importance in the pharmaceutical and several other industries and in the regeneration of waste solvent mixtures.

The main advantage of batch distillation over continuous is that a single apparatus can process many different liquid mixtures. Even multicomponent mixtures can be separated by batch distillation in a single column.

Many mixtures form an azeotrope, whose position can be shifted substantially by changing system pressure, that is, a pressure sensitive azeotrope.

Lewis (1928) was the first, who suggested to distil azeotropic mixtures by pressure swing distillation. This process has been suggested to separate azeotropic mixtures by e.g. Black, 1980; Abu-Eishah and Luyben, 1985; Chang and Shis, 1989.

Knapp et al. (1992) developed a new process, in which pressure swing continuous distillation was combined with entrainer addition. The possibility of the application of an entrainer for the separation of binary azeotropic mixtures increases to a large extent the number of mixtures separable by this process.
Repke et al. (2006) investigated the separation of a minimum boiling, homoazeotropic mixture (acetonitrile-water) by pressure swing distillation in a batch rectifier and in a stripper. The results were presented by pilot-plant measurements and rigorous simulations. The aim of the authors was rather the experimental study of the batch pressure swing distillation than the exhausting theoretical study of feasibility of the process. The above authors did not study either the separation of max. azeotropes or the application of the middle vessel column (MVC).

The aim of our paper is to study the pressure swing batch distillation (PSBD) separation of binary homoazeotropes by feasibility studies. Besides studying the well known configurations (rectifier, stripper, MVC) we also suggest two novel configurations such as double column batch rectifier (DCBR) and double column batch stripper (DCBS).

\section{FEASIBILITY STUDIES}

First the method applied for the assessment of feasibility is briefly presented, and then the feasibility of different column configurations will be investigated.

\subsection{Feasibility method}

When making feasibility studies we suppose that maximal (perfect) separation can be produced. This involves the following assumptions:

-infinite number of stages,

-very high reflux/reboil ratio, -negligible liquid plate hold-up, -negligible vapour hold-up. 
The method is based on the determination of the feasible compositions of products (continuously withdrawn) and those of residues (remaining in the vessel). Since we consider only binary mixtures for the feasibility analysis, we use the $y-x$ binary equilibrium diagram (Fig. 1) and instead of feasibility region we speak about feasibility interval. (Contrary to ternary mixtures binary (zeotropic) mixtures can be separated into their pure components in one step in a batch column.)
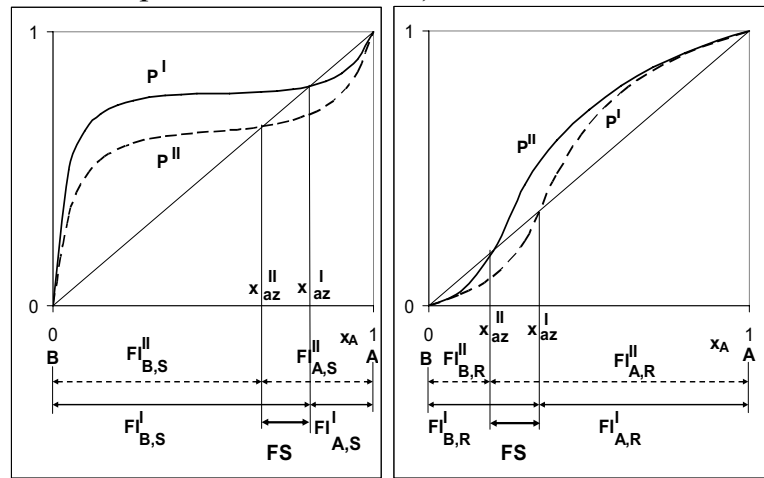

Fig. 1. Feasibility intervals of PSD

a. min. azeotrope

b. max. azeotrope

We distinguish two different feasibility intervals:

-Feasibility interval of a component $\left(\mathrm{FI}_{\mathrm{A}}\right.$ or $\left.\mathrm{FI}_{\mathrm{B}}\right)$ :

all feed compositions $(z)$, from where the given component can be produced by maximal separation as pure (top or bottom) product.

-Feasibility interval of the binary separation (FI): all feed compositions, from where both components can be purely produced by maximal separation at the given pressure or by applying pressure swing, that is, two different pressures. The necessary and sufficient conditions of the feasibility of the binary separation:

(i) the two component feasibility intervals have a common section (separation feasibility interval), and (ii) the feed composition is located in this common interval.

\section{Feasibility intervals for different types of mixtures}

\section{a. Zeotropic mixture}

From any binary feed $(0<z<1)$ pure $\boldsymbol{A}$ can be produced as top, pure $\boldsymbol{B}$ as bottom product, respectively. The feasibility intervals of components $\boldsymbol{A}\left(\mathrm{FI}_{\mathrm{A}}\right)$ and $\boldsymbol{B}\left(\mathrm{FI}_{\mathrm{B}}\right)$ are the same and have the maximum length possible: $0<z<1$. The feasibility interval of separation $\boldsymbol{A} / \boldsymbol{B}$ is also $0<z<1$, that is, the separation is feasible for any (binary) feed composition (the separation feasibility interval covers the whole feed composition region).

b. Minimum boiling point azeotropic mixture

Both pure components can be obtained at the bottom (at any pressure). At a given pressure (e.g. at $P^{\mathrm{I}}$ ) the two component feasibility intervals are separated by the azeotropic point $x_{\mathrm{az}}^{\mathrm{I}}$, that is, they have no common section (Fig. 1a):

$$
\mathrm{FI}_{\mathrm{A}}{ }^{\mathrm{I}}: x_{\mathrm{az}}^{\mathrm{I}}<\mathrm{z}<1 \quad \mathrm{FI}_{\mathrm{B}}{ }^{\mathrm{I}}: 0<z<x_{\mathrm{az}}^{\mathrm{I}}
$$

If the pressure is changed to $\mathrm{P}^{\mathrm{II}}$, the feasibility intervals of both components are shifting:

$$
\mathrm{FI}_{\mathrm{A}}{ }^{\mathrm{II}}: \mathrm{x}^{\mathrm{II}}{ }_{\mathrm{az}}<\mathrm{Z}<1 \quad \mathrm{FI}_{\mathrm{B}}{ }^{\mathrm{II}}: 0<\mathrm{Z}<\mathrm{x}^{\mathrm{II}}{ }_{\text {az }}
$$

The interval between the $x_{\mathrm{az}}^{\mathrm{I}}$ and $x_{\mathrm{az}}^{\mathrm{II}}$ is now a common section (FS) of the feasibility intervals of the two different components $\left(\mathrm{FI}_{\mathrm{B}}{ }^{\mathrm{I}}\right.$ and $\left.\mathrm{FI}_{\mathrm{A}}{ }^{\mathrm{II}}\right)$. Hence pure $\boldsymbol{B}$ and pure $\boldsymbol{A}$ can be produced as bottom product with a continuous process or a batch stripper at $P^{\mathrm{I}}$ and $P^{\mathrm{II}}$, respectively. In a batch rectifier only azeotropic mixtures can be withdrawn as product and pure components remain in the bottom vessel as residue.

c. Maximum boiling point azeotropic mixture

Both pure components can be obtained at the top (at any pressure). At a given pressure (e.g. at $P^{\mathrm{I}}$ ) the two component feasibility intervals are separated by the azeotropic point $x_{\mathrm{az}}^{\mathrm{I}}$ :

$$
\mathrm{FI}_{\mathrm{A}}{ }^{\mathrm{I}}: x_{\mathrm{az}}^{\mathrm{I}}<z<1 \quad \mathrm{FI}_{\mathrm{B}}{ }^{\mathrm{I}}: 0<z<x_{\mathrm{az}}^{\mathrm{I}}
$$

If the pressure is changed to $P^{\mathrm{II}}$, the feasibility intervals of both components are shifting:

$$
\mathrm{FI}_{\mathrm{A}}{ }^{\mathrm{II}}: x_{\mathrm{az}}^{\mathrm{II}}<z<1 \quad \mathrm{FI}_{\mathrm{B}}{ }^{\mathrm{II}}: 0<z<x_{\text {az }}{ }^{\mathrm{II}}
$$

The interval between the $x_{\mathrm{A}, \mathrm{az}}^{\mathrm{II}}$ and $x_{\mathrm{A}, \mathrm{az}}^{\mathrm{I}}(\mathrm{FS})$ is a common section of $\mathrm{FI}_{\mathrm{B}}{ }^{\mathrm{I}}$ and $\mathrm{FI}_{\mathrm{A}}{ }^{\mathrm{II}}$. Hence pure $\boldsymbol{B}$ and pure $\boldsymbol{A}$ can be produced as top product with a continuous process or a batch rectifier at $P^{\mathrm{I}}$ and $P^{\mathrm{II}}$, respectively. In a batch stripper only azeotropic mixtures can be withdrawn as product and pure components remain in the top vessel as residue.

\subsection{Different batch column configurations}

The BPSD can be realised in configurations with either one or two column sections. Because of the occurrence of the azeotrope the two pure components must be produced at two different pressures.

\subsubsection{Configurations with one column section}

The pressure swing can be performed only in the time so there must be at least two sequential production steps. At the two different pressures we can use either

a. the same configuration or

b. two different configurations.

\section{a. PSBD in a batch rectifier or in a batch stripper}

The feed is charged into the bottom (rectifier, Fig. 2a) or top vessel (stripper, Fig. 2b). Products are continuously withdrawn from the top (rectifier) or the bottom (stripper) into product tanks.

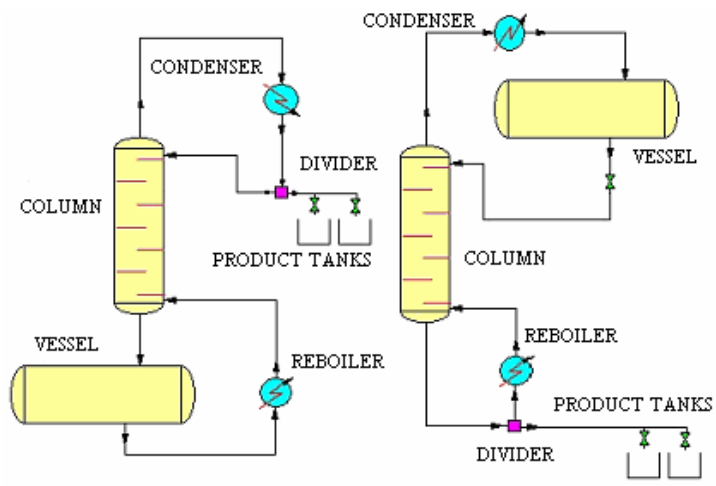

Fig. 2. Scheme of the batch rectifier (a) and stripper (b)

Depending on the feed concentration and the type of the azeotrope the first (and the following) product withdrawn can be pure $\boldsymbol{A}$, pure $\boldsymbol{B}$ or the azeotropic mixture (Appendices 1-2 (BR) and 3-4 (BS)). If in a step the product withdrawn is the azeotrope, before the next step it is necessary to empty the vessel and then to fill this azeotropic product into it.

We can conclude that all cases are feasible, that is, both the min. and max. azeotropes can be theoretically separated by PSBD in both the rectifier 
and the stripper, because we can produce both pure $\boldsymbol{A}$ and pure $\boldsymbol{B}$ by both configurations.

A production cycle consists of two rectification (BR) or stripping (BS) steps performed at different pressures $\left(P^{\mathrm{I}}\right.$ and $\left.P^{\mathrm{II}}\right)$. (One step is performed at the lower $\left(P^{\mathrm{L}}\right)$ and the other at the higher $\left(P^{\mathrm{H}}\right)$ pressure, respectively.) Even in the case of maximal separation the recovery of the pure components, which can be obtained in one cycle is limited and it depends on -the feed $(z)$ and the azeotropic compositions $\left(x_{\mathrm{az}}^{\mathrm{I}}\right.$ and $x_{\text {az }}^{\text {II }}$ and

-the sequence of the pressures in the cycle $\left(P^{\mathrm{I}}, P^{\mathrm{II}}\right.$ or $\left.P^{\mathrm{II}}, P^{\mathrm{I}}\right)$.

By the lever rule the total amount of the two pure products of the 1-st cycle from one mol feed:

$$
\frac{S W_{A}+S W_{B}}{F}=\frac{z-x_{a z}^{I I}}{1-x_{a z}^{I I}}+\frac{1-z}{1-x_{a z}^{I I}} * \frac{x_{a z}^{I}-x_{a z}^{I I}}{x_{a z}^{I}} \text { or } \frac{x_{a z}^{I}-z}{x_{a z}^{I}}+\frac{z}{x_{a z}^{I}} * \frac{x_{a z}^{I}-x_{a z}^{I I}}{1-x_{a z}^{I I}}
$$

The recoveries of both components can be increased by increasing the number of cycles.

\section{b. Combination of rectification and stripping}

If we have a column with two vessels (Fig. 3), one at the bottom and another at the top of the column, we can combine the pressure swing with changing of the operation mode. There is a common column section (either rectifying or stripping section depending on the step), total reboiler and a total condenser. The product tank of the rectifier will be the top vessel and its bottom vessel the product tank of the stripper in the next step, respectively.

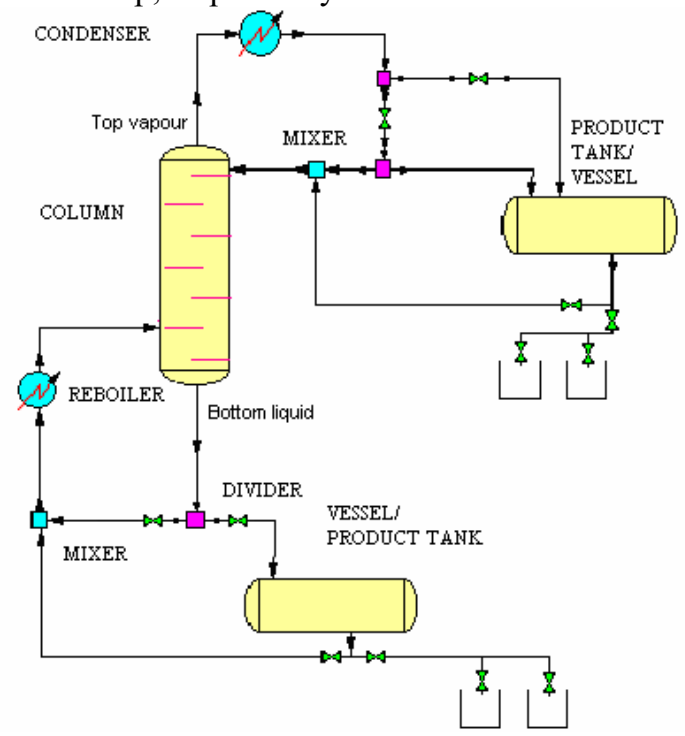

Fig. 3. Combination of a rectifier and a stripper

The separation is feasible only in the case, if in each step the product continuously withdrawn is the azeotrope, that is, for a minimum azeotrope we have to begin with rectification and for a maximum azeotrope with stripping, respectively. One of the two pure components remains in the vessel, which must be emptied before the next step.

\subsubsection{Configurations with two column sections}

The configurations with two column sections operated at different pressures can provide the possibility of the simultaneous production of the two pure components. First the middle vessel column then two new configurations will be investigated.

\section{a. Middle vessel column}

The feed is charged into the middle vessel (Fig. 4). Products are continuously withdrawn from the top and the bottom. In the rectifying and stripping sections different pressures are applied.

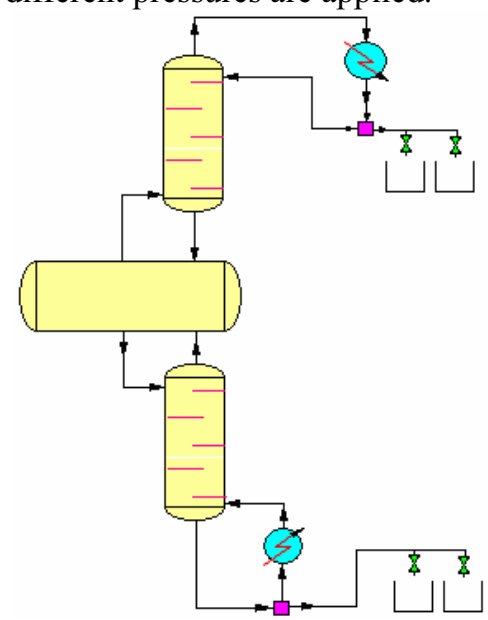

Fig. 4. Scheme of the middle vessel column

Depending on the relation between the pressures of the rectifying (RS) and stripping (SS) sections and the middle vessel (MV) four different alternatives are possible:

$$
\begin{aligned}
& \text { 1. } P_{\mathrm{RS}}>>P_{\mathrm{MV}}=P_{\mathrm{SS}} \\
& \text { 2. } P_{\mathrm{RS}}=P_{\mathrm{MV}}>>P_{\mathrm{SS}} \\
& \text { 3. } P_{\mathrm{RS}}=P_{\mathrm{MV}}<<P_{\mathrm{SS}} \\
& \text { 4. } P_{\mathrm{RS}}<<P_{\mathrm{MV}}=P_{\mathrm{RS}}
\end{aligned}
$$

From the aspect of the feasibility, it does not matter, that at the pressure of which section is the vessel operated, that is, there is no difference between the 1 st and 2 nd and between the 3rd and 4th cases, respectively. We summarised the possible products and residues in Appendix 5 and 6.

We can state that the separation is not feasible, because in all cases one of the two products is azeotrope, that is, we can not produce pure $\boldsymbol{A}$ and pure $\boldsymbol{B}$ simultaneously.

It is obvious that the evolution of the vessel composition strongly depends on the ratio of molar flow rates of the two products. However it can be stated that we can not have pure $\boldsymbol{B}$ (or $\boldsymbol{A}$ ) in the vessel while one of the products withdrawn is $\boldsymbol{A}$ (or B).

We can conclude the MVC can not be efficiently applied for binary PSBD.

\subsection{Novel batch column configurations}

The MVC containing two different (one rectifying and one stripping) sections has not proved to be suitable for PSBD. Now we consider if two new configurations with two identical column sections (operated at different pressures) and a common vessel can be used for PSBD, that is,

1. Double column batch rectifier (DCBR) for maximum azeotropes.

2. Double column batch stripper (DCBS) for minimum azeotropes. 


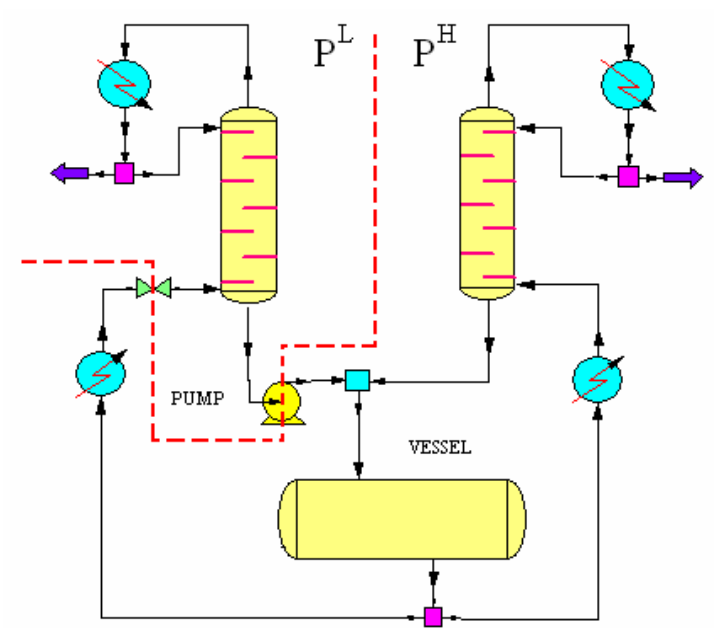

Fig. 5. Scheme of a double column batch rectifier

\subsubsection{Double column batch rectifier for maximum azeotropes}

The liquid streams flowing down from the two rectifying sections (Fig. 5) are mixed together in the bottom vessel operated at the higher pressure $\left(P^{\mathrm{H}}\right)$. The pressure of the liquid arriving from the column of lower pressure $\left(P^{\mathrm{L}}\right)$ must be increased with a pump. The liquid leaving the vessel is divided into two parts. In both branches there is a heat exchanger operated at $P^{\mathrm{H}}$. In the branch of light pressure it is enough to vaporise partially the liquid since the remaining liquid can be vaporised due to the decrease of pressure on the valve. In the branch of high pressure there is a total reboiler.

In the case of maximum azeotropes the top products can be pure components.

\subsubsection{Double column batch stripper for minimum azeotropes}

The condensates of vapour streams from the top of the two stripping sections (Fig. 6) are mixed together in the top vessel operated at the lower pressure. The pressure of the vapour arriving from the column of higher pressure is decreased with a valve before the condenser. The liquid leaving the vessel is divided into two parts. The pressure of the reflux of high pressure column must be increased with a pump (the reflux will be always subcooled liquid). At the bottom of both columns there is a divider and a total reboiler. In the case of minimum azeotropes the bottom products can be pure components.

For both configurations the products of the two columns can be the two pure components, if the vessel composition is found between the two azeotropic compositions (in the feasibility interval of the separation). This means that the vessel composition must be kept in this interval from beginning to end of the production. If the feed composition is out of this interval, it is necessary to apply a preliminary step, when product is withdrawn from only one column until the vessel composition enters this interval.

We can choose such a ratio of the two product flow rates $\left(W^{\mathrm{L}} / W^{\mathrm{H}}\right)$ where the vessel composition does not change and so both column sections can be operated in steady-state during the production.

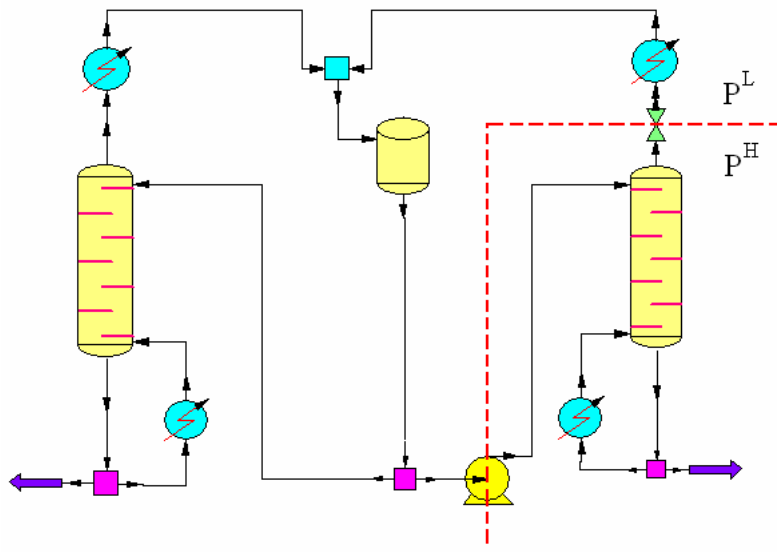

Fig. 6. Scheme of a double column batch stripper

These column configurations have the following main advantages:

-the separation $\boldsymbol{A} / \boldsymbol{B}$ is possible with only one production step,

-the two columns are operating simultaneously, so they can be thermally integrated,

-the dimension (number of stages, diameter) of the two columns can be different (higher flexibility),

-both column sections can be operated in steadystate; there is no pressure change during the process.

\section{RESULTS FOR THE FEASIBLE CONFIGURATIONS}

In the next the evolution of the (top/bottom) product(s) $\left(x_{\mathrm{W}}\right)$ and the (bottom/top) vessel residue(s) $\left(x_{\mathrm{VR}}\right)$ compositions will be studied for the different configurations.

Besides the assumption of maximal separation we still suppose that the flow rate of the product(s) and the reflux/reboil ratio does not vary in time ( $W=$ const., $R=$ const. or $R_{\mathrm{s}}=$ const.) and that at the start of the process the feed composition is already located between the two azeotropic compositions.

First the configurations with only one column section (BR (for max. azeotropes) or BS (for min. azeotropes), then their combination) and finally those with two column sections (DCBR (for max. azeotropes) or DCBS (for min. azeotropes)) will be considered.

\subsection{Batch rectifier for maximum azeotropes or batch stripper for minimum azeotropes}

If we separate a mixture forming a maximum azeotrope in a BR or minimum azeotrope in a BS we can alternately produce pure components (Fig. 7). In a later (k-th) cycle

-the duration of the steps gets shorter (the quantity of the pure components produced in this cycle $\left(S W_{\mathrm{i}, \mathrm{k}}\right)$ proportionally decreases),

-the variation of the vessel composition between the two azeotropic compositions will be quicker $\left(\left|\mathrm{d} x_{\mathrm{VR}} / \mathrm{dt}\right|\right.$ increases $)$ due to the decrease of the vessel hold-up. 


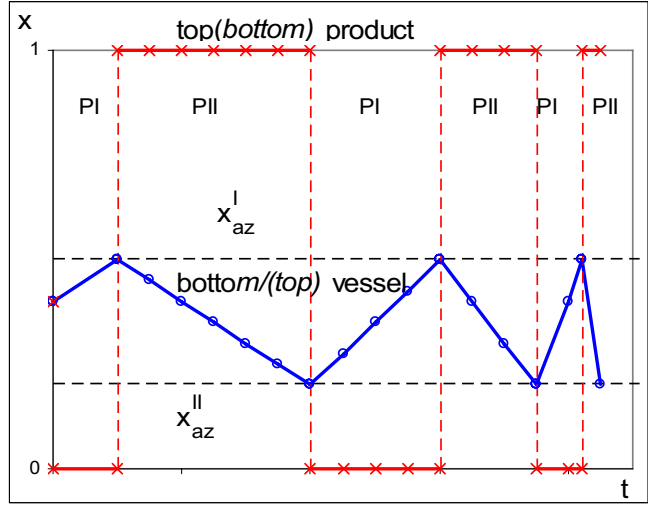

Fig. 7. Evolution of the product and vessel compositions of the BR (BS) for max. ( $\mathrm{min}$.) azeotropes

3.2 Combination of the batch rectifier and stripper for maximum and minimum azeotropes If we separate an azeotropic mixture by the method described in Chapter 2.2.1b, the two different configurations are sequentially applied. This method can be applied for both maximum and minimum azeotropes. The evolution of the composition of the flows leaving the column section (top vapour $\left(y_{\mathrm{TV}}\right)$ and bottom liquid $\left(x_{\mathrm{BL}}\right)$ is similar for the two cases (Fig. 8, the separation of minimum azeotropes is denoted with Italic characters within brackets)

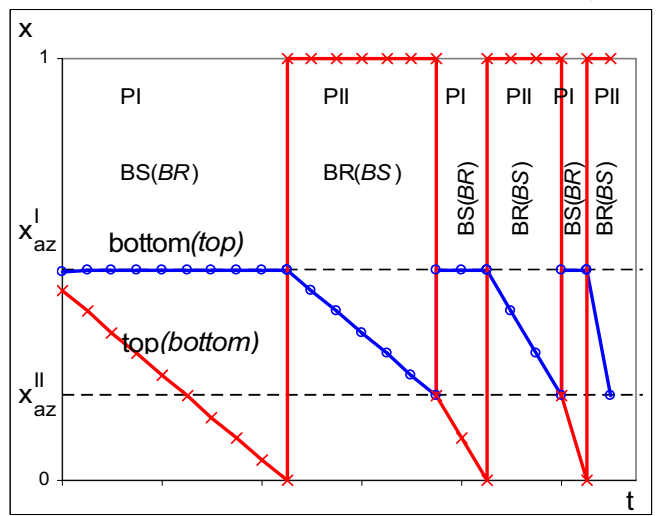

Fig. 8. Evolution of top vapour and bottom liquid compositions of the BR-BS for max. (min.) azeotropes

We can alternately produce pure components at the top (bottom)

- as vessel residue in the stripping (rectifying) steps,

- continuously as product in the rectifying (stripping) steps.

The bottom liquid (top vapour) composition remains between the two azeotropic ones:

-in the stripping (rectifying) steps it is constant (equals to one of the azeotropic compositions),

-in the rectifying (stripping) steps it varies continuously and at the end of the step it reaches the azeotropic composition for the pressure of this step.

With the progress of the process

-the duration of the steps gets shorter (the quantity of the pure components produced in this cycle $\left(S W_{\mathrm{i}, \mathrm{k}}\right.$ or $S R_{\mathrm{i}, \mathrm{k}}$ ) also decreases),

-the variation of the vessel composition between the two azeotropic compositions will be quicker $\left(\left|\mathrm{d} x_{\mathrm{VR}} / \mathrm{dt}\right|\right.$ increases $)$ due to the decrease of the quantity of mixture to be separated (decrease of top and bottom vessel hold-ups).

The top vessel is filled up before each stripping step (in the 1-st cycle with the feed, then with the residue of the previous rectifying step) and is drained after each stripping step into a product tank (for component $\boldsymbol{B}$ or $\boldsymbol{A}$ depending on the first process step pressure). In the rectifying steps the distillate is continuously collected in a product tank (for component $\boldsymbol{A}(\boldsymbol{B})$ ).

\subsection{Double column batch rectifier for maximum or stripper for minimum azeotropes}

We can continuously produce pure $\mathbf{A}$ and $\boldsymbol{B}$ (Fig. 9) -with a double column batch rectifier (as distillate) from a mixture forming a maximum azeotrope or -with a double column batch stripper (as bottoms) from a mixture forming a minimum azeotrope.

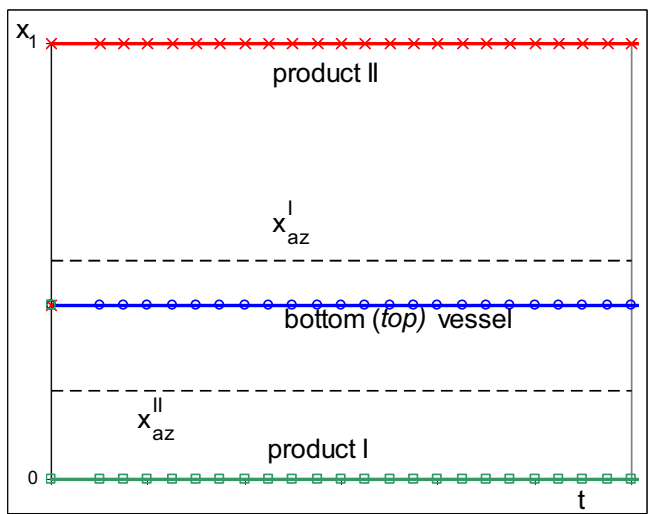

Fig. 9. Evolution of product and vessel compositions of the DCBR (DCBS) for max. (min.) azeotropes

The vessel composition can be kept constant and so the two column sections can be operated under steady state conditions. With the progress of the process the vessel hold-up continuously decreases.

Since maximal separation can not be produced in the practice we made also rigorous simulation calculations for real operating conditions to be published elsewhere (Modla and Lang, 2007).

\section{CONCLUSION}

The feasibility of the binary pressure swing distillation in different batch column configurations was investigated by assuming maximal separation. We can apply the different pressures separating them - either in time in one column section (batch rectifier and stripper)

- or in space in two column sections (e.g. MVC).

We stated that the middle vessel column (MVC) is not suitable for the PSBD process.

We suggested two novel configurations: the double column batch rectifier (DCBR) and double batch column stripper (DCBS). These new flexible column configurations have several advantages:

-there is only one production step, the two components can be produced simultaneously,

-both column sections can be operated in steadystate, there is no pressure change during the process, -the two columns can be thermally integrated. 
The separation of both minimum and maximum azeotropes is feasible by the alternate application of a batch rectifier and stripper.

\section{REFERENCES}

Abu-Eishah S. I., Luyben W. L. "Design and Control of Two-Column Azeotropic Column Azeotropic Distillation System", Ind. Eng. Chem. Process. Des. Dev. 24, 132-140 (1985).

Black C. "Distillation Modelling of Ethanol Recovery and Dehydration Processes for Ethanol and Gasahol", Chem. Eng. Prog., 76, 78-85, (1980).

Chang T., Shih T. T. "Development of an Azeotropic Distillation Scheme for Purification of Tetrahydrofuran", Fluid Phase Equilib., 52, 161, 161-168. (1989).

Chemstations, "CHEMCAD User Guide" (2005).

Knapp J. P. and M. F. Doherty "A new pressure swing-distillation process for separating homogeneous Azeotropic Mixtures", Ind. Eng. Chem. Res., 31, 346-357, (1992).

Modla G. and P. Lang "New column configurations for pressure swing batch distillation II. Rigorous Simulation Results", DYCOPS2007.

Perry R. H., D.W. Green, J.O. Maloney, "Perry's Chemical Engineer's Handbook" 7th edition, McGraw Hill, New York, (1997).

Lewis W. K. "Dehydrating Alcohol and the Like", U.S. Patent, 1,676,700, July 10, (1928).

Repke .J. U., Klein A., Bogle D., Wozny G., "Pressure Swing Batch Distillation for Homogenous Azeotropic Separation”,D\&A2006,London, 709-718.

\section{ACKNOWLEDGEMENT}

This work was financially supported by the Hungarian Scientific Research Fund (OTKA, T049184) and National Office for Research and Technology (KPI, GVOP-3.1.1.-2004-05-0544/3.0).

\section{APPENDIX}

Feasible products and residues in the different steps.

Appendix 1. Batch rectifier for min. azeotropes (Start at $\left.P^{\mathrm{I}}\right)$

\begin{tabular}{|c|c|c|c|}
\hline Step/Feed & $\mathbf{0}<z<x^{\mathrm{II}}{ }_{\mathrm{az}}$ & $x_{\mathrm{az}}^{\mathrm{II}}<\mathrm{z}<x_{\mathrm{az}}^{\mathrm{I}}$ & $x_{\mathrm{az}}^{\mathrm{I}}<\mathrm{z}<1$ \\
\hline $\begin{array}{l}\text { 1st }\left(\mathrm{P}^{\mathrm{I}}\right) \text {, cycle } 1 \\
\text { Top product } \\
\text { Bottom residue }\end{array}$ & $\begin{array}{c}x_{\mathrm{az}}^{\mathrm{I}} \\
\boldsymbol{B}\end{array}$ & $\begin{array}{c}x_{\mathrm{az}}^{\mathrm{I}} \\
\boldsymbol{B}\end{array}$ & $\underset{\boldsymbol{A}}{x_{\mathrm{az}}^{\mathrm{I}}}$ \\
\hline $\begin{array}{l}* 2 \text { nd }\left(\mathrm{P}^{\mathrm{II}}\right) \\
\text { Top product } \\
\text { Bottom residue }\end{array}$ & $x^{\mathrm{II}}{ }_{\boldsymbol{a z}}$ & $x^{\mathrm{II}}{ }_{\boldsymbol{a} z}^{\mathrm{A}}$ & $\underset{\boldsymbol{A}}{x_{\mathrm{az}}^{\mathrm{II}}}$ \\
\hline $\begin{array}{l}* 1 \text {-st }\left(\mathrm{P}^{\mathrm{I}}\right) \text {, cycle } 2 \\
\text { Top product } \\
\text { Bottom residue }\end{array}$ & $\begin{array}{c}x_{\mathrm{az}}^{\mathrm{I}} \\
\boldsymbol{B}\end{array}$ & $\begin{array}{c}x_{\mathrm{az}}^{\mathrm{I}} \\
\boldsymbol{B}\end{array}$ & $\begin{array}{c}x_{\mathrm{az}}^{\mathrm{I}} \\
\boldsymbol{B}\end{array}$ \\
\hline
\end{tabular}

*In this step the previous top product is recharged to the bottom vessel.

Appendix 2. Batch rectifier for max. azeotropes a. Start at $\mathrm{P}^{\mathrm{I}}$

\begin{tabular}{|l|c|c|c|}
\hline Step/Feed & $\mathbf{0}<z<\boldsymbol{x}^{\mathrm{II}}{ }_{\mathrm{az}}$ & $\boldsymbol{x}_{\mathrm{az}}^{\mathrm{II}}<\boldsymbol{z}<\boldsymbol{x}_{\mathrm{az}}^{\mathrm{I}}$ & $\boldsymbol{x}_{\mathrm{az}}^{\mathrm{I}}<\boldsymbol{z}<\mathbf{1}$ \\
\hline 1st $\left(\mathrm{P}^{\mathrm{I}}\right)$, cycle 1 & $\boldsymbol{B}$ & $\boldsymbol{B}$ & $\boldsymbol{A}$ \\
Top product & $\boldsymbol{B}$ & $\boldsymbol{B}$ & $x_{\mathrm{az}}^{\mathrm{I}}$ \\
Bottom residue & $x_{\mathrm{az}}^{\mathrm{I}}$ & $x_{\mathrm{az}}^{\mathrm{I}}$ & \\
\hline 2nd $\left(\mathrm{P}^{\mathrm{II}}\right)$ & & & $\boldsymbol{A}$ \\
Top product & $\boldsymbol{A}$ & $\boldsymbol{A}$ & $\boldsymbol{A}$ \\
Bottom residue & $x_{\mathrm{az}}^{\mathrm{II}}$ & $x_{\mathrm{az}}^{\mathrm{II}}$ & $x_{\mathrm{az}}^{\mathrm{II}}$ \\
\hline 1st $\left(\mathrm{P}^{\mathrm{I}}\right)$ cycle 2 & & & \\
Top product & $\boldsymbol{B}$ & $\boldsymbol{B}$, & $\boldsymbol{B}$ \\
Bottom residue & $x_{\mathrm{az}}^{\mathrm{I}}$ & $x_{\mathrm{az}}^{\mathrm{I}}$ & $x_{\mathrm{az}}^{\mathrm{I}}$ \\
\hline
\end{tabular}

b. Start at $P^{\mathrm{II}}$

\begin{tabular}{|c|c|c|c|}
\hline Step/Feed & $0<z<x_{a z}^{I I}$ & $\boldsymbol{x}_{\mathrm{az}}^{\mathrm{II}}<\boldsymbol{z}<\mathbf{x}_{\mathrm{az}}^{\mathrm{I}}$ & $x_{a z}^{1}<z<1$ \\
\hline $\begin{array}{l}1 \text { st }\left(\mathrm{P}^{\mathrm{II}}\right) \text {, cycle } 1 \\
\text { Top product } \\
\text { Bottom residue }\end{array}$ & $\underset{x_{\mathrm{az}}^{\mathrm{II}}}{\boldsymbol{B}}$ & $\underset{x^{\mathrm{II}}}{\boldsymbol{A}}$ & $\underset{x_{\mathrm{az}}^{\mathrm{II}}}{\boldsymbol{A}}$ \\
\hline $\begin{array}{l}\text { 2nd }\left(\mathrm{P}^{1}\right) \\
\text { Top product } \\
\text { Bottom residue }\end{array}$ & $\underset{x_{\mathrm{az}}^{\prime}}{\boldsymbol{B},}$ & $\begin{array}{c}\boldsymbol{B} \\
x_{\mathrm{az}}^{\mathrm{I}}\end{array}$ & $\underset{x_{\mathrm{az}}^{\mathrm{B}}}{\boldsymbol{B}}$ \\
\hline $\begin{array}{l}1 \text { st }\left(\mathrm{P}^{\mathrm{I}}\right), \text { cycle } 2 \\
\text { Top product } \\
\text { Bottom residue }\end{array}$ & $\begin{array}{c}\boldsymbol{A} \\
X_{\mathrm{az}} \\
\end{array}$ & $\begin{array}{c}\boldsymbol{A} \\
x_{\mathrm{IIz}}\end{array}$ & $\underset{x_{\mathrm{az}}^{\mathrm{II}}}{\boldsymbol{A}}$ \\
\hline
\end{tabular}

Appendix 3. Batch stripper for min. azeotropes a. Start at $P^{\mathrm{I}}$

\begin{tabular}{|c|c|c|c|}
\hline Steps/Feed & $0<z<x_{\text {az }}^{\text {II }}$ & $x_{\mathrm{az}}^{\mathrm{II}}<\mathrm{z}<x_{\mathrm{az}}^{\mathrm{I}}$ & $x_{\mathrm{az}}^{\mathrm{I}}<\mathrm{z}<1$ \\
\hline $\begin{array}{l}1 \text { st }\left(\mathrm{P}^{\mathrm{I}}\right) \text {, cycle } 1 \\
\text { Top residue } \\
\text { Bottom product }\end{array}$ & $\begin{array}{c}\boldsymbol{B} \\
x_{\mathrm{az}}^{\mathrm{I}}\end{array}$ & $\underset{x_{\mathrm{az}}^{\mathrm{B}}}{\boldsymbol{B}}$ & $\underset{x_{\mathrm{az}}^{\mathrm{I}}}{\boldsymbol{A}}$ \\
\hline $\begin{array}{l}\text { 2nd }\left(\mathrm{P}^{\mathrm{II}}\right) \\
\text { Top residue } \\
\text { Bottom product }\end{array}$ & $\underset{x_{\mathrm{az}}^{\mathrm{II}}}{\boldsymbol{A}}$ & $\underset{x_{\mathrm{az}}^{\mathrm{II}}}{\boldsymbol{A}}$ & $\underset{x_{\mathrm{az}}^{\mathrm{II}}}{\boldsymbol{A}}$ \\
\hline $\begin{array}{l}\text { 1st }\left(\mathrm{P}^{\mathrm{I}}\right) \text {, cycle } 2 \\
\text { Top residue } \\
\text { Bottom product }\end{array}$ & $\begin{array}{c}\boldsymbol{B} \\
x_{\mathrm{az}}^{\mathrm{I}}\end{array}$ & $\underset{x_{\mathrm{az}}^{\mathrm{B}}}{\boldsymbol{B},}$ & $\begin{array}{c}\boldsymbol{B} \\
x_{\mathrm{az}}^{\mathrm{I}}\end{array}$ \\
\hline \multicolumn{4}{|l|}{ b. Start at $P^{\mathrm{II}}$} \\
\hline Steps/Feed & $0<z<x_{\text {az }}^{\text {II }}$ & $x_{\mathrm{az}}^{\mathrm{II}}<\mathrm{z}<\boldsymbol{x}_{\mathrm{az}}^{\mathrm{I}}$ & $x_{\mathrm{az}}^{1}<z<1$ \\
\hline $\begin{array}{l}1 \text { st }\left(\mathrm{P}^{\mathrm{II}}\right) \text {, cycle } 1 \\
\text { Top residue } \\
\text { Bottom product }\end{array}$ & $\underset{x_{\mathrm{az}}^{\mathrm{II}}}{\boldsymbol{B}}$ & $\underset{x_{\mathrm{az}}^{\mathrm{II}}}{\boldsymbol{A}}$ & $\underset{x_{\mathrm{az}}^{\mathrm{II}}}{\boldsymbol{A}}$ \\
\hline $\begin{array}{l}\text { 2nd }\left(\mathrm{P}^{\mathrm{l}}\right) \\
\text { Top residue } \\
\text { Bottom product }\end{array}$ & $\underset{x_{\mathrm{az}}^{\mathrm{I}}}{\boldsymbol{B}}$ & $\underset{x_{\mathrm{az}}^{\mathrm{I}}}{\boldsymbol{B}}$ & $\underset{x_{\mathrm{az}}^{\mathrm{I}}}{\boldsymbol{B}}$ \\
\hline $\begin{array}{l}1 \text { st }\left(\mathrm{P}^{\mathrm{l}}\right) \text {, cycle } 2 \\
\text { Top residue } \\
\text { Bottom product }\end{array}$ & $\underset{x^{\mathrm{II}}}{\boldsymbol{A}}$ & $\underset{x_{\mathrm{az}}^{\mathrm{II}}}{\boldsymbol{A}}$ & $\underset{x^{I I}{ }_{\mathrm{az}}^{A}}{\boldsymbol{A}}$ \\
\hline
\end{tabular}

Appendix 4. Batch stripper for max. azeotropes (Start at $P^{\mathrm{I}}$ )

\begin{tabular}{|c|c|c|c|}
\hline Steps/Feed & $\overline{0}<z<x_{\text {az }}^{I_{1 I}}$ & $\boldsymbol{x}_{\mathrm{az}}^{\mathrm{II}}<z_{z}<x_{\mathrm{az}}^{\mathrm{I}}$ & $x_{\mathrm{az}}^{\mathrm{I}}<\mathrm{z}<1$ \\
\hline $\begin{array}{l}\text { 1st }\left(\mathrm{P}^{\mathrm{I}}\right) \text {, cycle } 1 \\
\text { Top residue } \\
\text { Bottom product }\end{array}$ & $\begin{array}{c}x_{\mathrm{az}}^{\mathrm{I}} \\
\boldsymbol{B}\end{array}$ & $\begin{array}{c}x_{\mathrm{az}}^{\mathrm{I}} \\
\boldsymbol{B}\end{array}$ & $\begin{array}{c}x_{\mathrm{az}}^{\mathrm{I}} \\
\boldsymbol{A}\end{array}$ \\
\hline $\begin{array}{l}{ }^{*} 2 \text { nd }\left(\mathrm{P}^{\mathrm{II}}\right) \\
\text { Top residue } \\
\text { Bottom product }\end{array}$ & $\begin{array}{c}x_{\mathrm{az}}^{\mathrm{II}} \\
\boldsymbol{A}\end{array}$ & $\underset{\mathrm{A}}{x_{\mathrm{az}}^{\mathrm{II}}}$ & $\begin{array}{c}x_{\mathrm{az}}^{\mathrm{II}} \\
\boldsymbol{A}\end{array}$ \\
\hline $\begin{array}{l}* 1 \text { st }\left(\mathrm{P}^{\mathrm{I}}\right) \text {, cycle } 2 \\
\text { Top residue } \\
\text { Bottom product }\end{array}$ & $\begin{array}{c}x_{\mathrm{az}}^{\mathrm{I}} \\
\boldsymbol{B}\end{array}$ & $\begin{array}{c}x_{\mathrm{az}}^{\mathrm{I}} \\
\boldsymbol{B}\end{array}$ & $\begin{array}{c}x_{\mathrm{az}}^{\mathrm{I}} \\
\boldsymbol{B}\end{array}$ \\
\hline
\end{tabular}

*In this step the previous bottom product is recharged to the top vessel.

Appendix 5. MVC for max. azeotropes a. $P_{\mathrm{SS}}=P^{\mathrm{I}}, P_{\mathrm{RS}}=P^{\mathrm{II}}$

\begin{tabular}{|c|c|c|c|}
\hline Products/Feed & $0<z<x^{I I}{ }_{a z}$ & $\boldsymbol{x}_{\mathrm{az}}^{\mathrm{II}}<\boldsymbol{z}<\boldsymbol{x}_{\mathrm{az}}^{\mathrm{I}}$ & $x_{\mathrm{az}}^{1}<z<1$ \\
\hline Bottom product & $x_{\text {az }}^{\mathrm{II}}$ & $x_{\mathrm{az}}^{\mathrm{II}}$ & $x_{\text {az }}^{\mathrm{II}}$ \\
\hline Top product & $B$ & $A$ & $A$ \\
\hline \multicolumn{4}{|c|}{ b. $P_{\mathrm{SS}}=P^{\mathrm{II}}, P_{\mathrm{RS}}=P^{\mathrm{I}}-$} \\
\hline Products/Feed & $0<z<x^{\mathrm{II}}{ }_{\text {az }}$ & $x_{\mathrm{az}}^{\mathrm{II}}<z<x_{\mathrm{az}}^{\mathrm{I}}$ & $x_{a z}^{1}<z<1$ \\
\hline Bottom product & $x_{\mathrm{az}}^{\mathrm{I}}$ & $x_{\mathrm{az}}^{\mathrm{I}}$ & $x_{\mathrm{az}}^{\mathrm{I}}$ \\
\hline Top product & $B$ & $A$ & $A$ \\
\hline
\end{tabular}

Appendix 6. MVC for min. azeotropes a. $P_{\mathrm{SS}}=P^{\mathrm{I}}, P_{\mathrm{RS}}=P^{\mathrm{II}}$

\begin{tabular}{|c|c|c|c|}
\hline Products/Feed & $0<z<x_{a z}^{I I}$ & $x_{\mathrm{az}}^{\mathrm{II}}<\mathrm{z}<\boldsymbol{x}_{\mathrm{az}}^{\mathrm{I}}$ & $x_{\mathrm{az}}^{\mathrm{I}}<z<1$ \\
\hline Bottom product & $B$ & $A$ & $A$ \\
\hline Top product & $x_{\mathrm{az}}^{1}$ & $x_{\mathrm{az}}^{I}$ & $x_{\mathrm{az}}^{1}$ \\
\hline \multicolumn{4}{|c|}{ b. $P_{\mathrm{SS}}=P^{\mathrm{II}}, P_{\mathrm{RS}}=P_{-}^{\mathrm{I}}$} \\
\hline Products/Feed & $0<z<x_{a z}^{I I}$ & $x_{\mathrm{az}}^{\mathrm{II}}<\mathrm{z}<x_{\mathrm{az}}^{\mathrm{I}}$ & $x_{\mathrm{az}}^{1}<z<1$ \\
\hline Bottom product & $B$ & $B$ & $A$ \\
\hline Top product & $x_{\mathrm{az}}^{\mathrm{II}}$ & $x_{\mathrm{az}}^{\mathrm{II}}$ & $x_{\mathrm{az}}^{\mathrm{II}}$ \\
\hline
\end{tabular}

